\title{
Influences of mechanical exposure biographies on physical capabilities of workers from automotive industry - a study on possible dose-response relationships and consequences for short and long term job rotation
}

\author{
Holger Rademacher ${ }^{\mathrm{a}}$, Ralph Bruder ${ }^{\mathrm{a}}$, Andrea Sinn-Behrendt ${ }^{\mathrm{a},{ }^{*}}$ and Kurt Landau ${ }^{\mathrm{a}}$ \\ ${ }^{a}$ Institute of Ergonomics, Department of Mechanical Engineering, Technische Universität Darmstadt, \\ Petersenstr. 30, D-64287 Darmstadt, Germany
}

\begin{abstract}
This paper describes a field study in production areas of a vehicle manufacturing plant, where 106 male workers (aged from 20 to 63 years) were examined and interviewed by the authors. Aim of study was to identify relationships between specific physical worker capabilities and doses of mechanical exposures using self-developed standardized questionnaires as well as a battery of work-specific tests.

The dependent variables are different "physical capabilities", classified using a five-point rating scale with regard to the grade of limitation of the respective capability. Independent variables are "age" and specific "mechanical exposures". Several exposures were combined and multiplied with their respective durations in order to determine doses on three different body regions - back, shoulder-neck and upper limbs.

There are significant positive correlations between "age" and "dose of mechanical exposure on back/shoulder-neck/upper limbs region". The analysis of the relationship between dose of exposure and different capabilities to lift or reposition loads (with variable weight) shows weak significant correlations for all three body regions. Data analysis shows no significant correlations between any dose of mechanical exposure and capabilities to work in awkward body postures.

These results should be considered in age management programs when scheduling future employee assignments to workplaces, especially for production systems where manual handling tasks are dominant.
\end{abstract}

Keywords: age management, mechanical exposures, musculoskeletal disorders, physical capabilities

\section{Introduction}

Age distributions of workforces in most industrial enterprises are continually shifting towards higher age in case of developed countries like Germany, Japan and even the United States of America. Older workers from production areas (e. g. in automotive industry) have generally experienced higher doses of mechanical exposures in comparison to their younger colleagues. Despite all measures to improve ergonomic design of industrial workplaces, there are still considerable deficits in terms of work conditions

*Corresponding author. A. Sinn-Behrendt; E-mail: sinn@iad.tu-darmstadt.de; Tel: +49 6151 162491 ; fax: +49 6151163488. 
found in recent studies using ergonomic screening of workplaces $[10,23]$ as well as surveys $[18,21]$. This leads to the question whether there are significant relationships between mechanical exposure biographies and physical capabilities that have practical implications for personnel planning, especially concerning the prevention of musculoskeletal disorders.

There are numerous epidemiologic studies showing associations between mechanical exposures at the workplace (manual materials handling, awkward body postures, repetitive loads on the upper extremities etc.) and the occurrence of musculoskeletal symptoms or disorders [reviews in 1-2, 7, 11, 20 and previous study by the authors of this article in 15].

Literature research didn't reveal any published study regarding the relationship between dose of mechanical exposure and physical capabilities. The majority of previous studies using a retrospective approach for analysis of mechanical exposures are focusing on specific musculoskeletal disorders [7].

Only one study by Weichel [27] showing preliminary results of an analysis of relationships between exposure biography and musculoskeletal symptoms has been found. They indicate existing but not very high correlations between exposures like "standing", "unfavorable body postures" or "lifting/carrying loads of more than $10 \mathrm{~kg}$ " and symptoms in the neck region, knee region as well as foot region.

\section{Methods}

All data was collected in a field study in cooperation with a German vehicle manufacturer where 106 male workers aged 20 to 63 years (mean $=40.34 \mathrm{yr}$, $\mathrm{SD}=11.72 \mathrm{yr}$ ) have been examined and interviewed. During data collection all subjects were employed in production areas of the plant. The subjects received a handout about the purpose and content of the examination. Furthermore, the subjects agreed to participation, recording of personal data (made anonymous) and video recording via signature on a consent form.

Three subjects had to be excluded from analysis because of missing information on questionnaire items measuring physical exposures. Another three subjects were excluded from analysis because of insufficient data for capability rating. Two major age groups are regarded in this study: the "younger workers" aged between 20 and 35 years as well as the "older workers" aged from 45 up to 63 years.
Subjects had to fulfill several criteria in order to be able to participate in the study. Their work experience had to be more than five years in job (incl. professional education), but they also had to be no more than six months out of job (unemployed or retired). Their actual job(s) must be characterized by predominantly physical work. Current receipt of disability pension, current inability to work or longer period(s) of incapacity for work (more than three months in the past twelve months because of disorders in musculoskeletal system including neurological disorders) were defined as criteria for exclusion from the study.

\subsection{Exposure biography}

In order to operationalize past and present mechanical exposures, the subjects experienced during their working life, a standardized self-developed questionnaire was used. It contains 20 items each representing a different mechanical exposure which is rated by the interviewee on a six-point ordinal scale concerning its frequency of occurrence $(0=$ never, $5=$ more than six hours per shift) during job. The rating is done for every single job the subject has done in his working life (in actual as well as previous companies). It starts with present job followed by professional education, first job after education and so on. If the subject had any questions, there has always been a trained interviewer to help him.

After a first data review several items from the questionnaire were selected for statistical analysis. Those items can be allocated to different exposure categories and especially body regions [e. g. 1, 11-12, 20 and 24], shown in Table 1.

Doses of mechanical exposure on the three body regions "back", "shoulder-neck" and "upper limbs" were calculated using a simple approach following Checkoway et al. [4] and Elsner et al. [9]:

$$
\text { does on body reglon }=\sum_{i=1}^{T} \sum_{i=1}^{j} x_{i} * d_{j}
$$

where $x_{i j}$ is the frequency of occurrence of exposure $i$ concerning job $j$ and $d_{j}$ is the duration of job $j$. 
Table 1

Mechanical exposures included in dose calculation and assignment to body region

\begin{tabular}{|c|c|c|}
\hline Body region & Exposure category & Mechanical exposure (item) \\
\hline \multirow[t]{7}{*}{ Back } & Manual materials handling & Lifting (load weight: $5-10$ kg) \\
\hline & & Lifting (load weight: $10-20 \mathrm{~kg}$ ) \\
\hline & & Lifting (load weight: more than $20 \mathrm{~kg}$ ) \\
\hline & & Pushing and pulling of loads \\
\hline & Awkward body postures & Trunk moderately bent forward $\left(20-60^{\circ}\right)$ \\
\hline & & Trunk strongly bent forward $\left(>60^{\circ}\right)$ \\
\hline & & Trunk rotation \\
\hline \multirow[t]{2}{*}{ Shoulder-neck } & Awkward body postures & Overhead work \\
\hline & & Neck inclination \\
\hline Upper limbs & Action forces & Work tasks involving high forces \\
\hline
\end{tabular}

Table 2

Physical worker capabilities rated on the basis of capability testing

\begin{tabular}{ll}
\hline Static arm posture at shoulder level & Static arm posture above head level \\
Trunk moderately bent forward $\left(20-60^{\circ}\right)$ & Trunk strongly bent forward $\left(>60^{\circ}\right)$ \\
$\begin{array}{l}\text { Lifting / repositioning of loads } \\
\text { between floor and waist level }(5 \text { to max. } 35 \mathrm{~kg})\end{array}$ & $\begin{array}{l}\text { Lifting / repositioning of loads } \\
\text { between waist and head level }(5 \mathrm{to} \mathrm{max.} 20 \mathrm{~kg})\end{array}$ \\
\hline
\end{tabular}

\subsection{Capability analysis}

The evaluation of physical worker capabilities is based on data from a specifically developed test procedure, which consists of a medical examination, an interview with several questionnaires (including the biography questionnaire) and physical, work-specific tests. Typical mechanical work-related exposures are represented in nine different work-specific tests, which have been developed on basis of more than 400 workplace analyses, conducted by the authors in several automotive companies. These tests include tasks like "Lifting between floor and waist level" or "Screwdriver use towards floor while trunk strongly bent forward" and are described in detail in [22].

Up to 20 different physical worker capabilities can be rated based on the measurement outcomes from the test battery using algorithms that integrate the variables from the work-specific tests and questionnaire data related to musculoskeletal symptoms in relevant body regions. Rating is done using a 5-point ordinal scale with regard to "grade of limitation" of the respective capability ( $0=$ no limitation; $4=$ strong limitation). To date six different capabilities have been rated (Table 2).

\subsection{Statistical analysis}

Relationships between the dependent variables physical capabilities shown in Table 2 - and independent variables - age and specific doses of mechanical exposures shown in Table 1 - are described statistically using calculation of Kendall-Tau correlation coefficients [13] and partial rank correlations [14]. 
Table 3

Relationships between doses of mechanical exposure and physical capabilities as well as between doses of mechanical exposure and age

\begin{tabular}{|c|c|c|c|}
\hline \multirow[t]{2}{*}{ Physical capability $^{\mathrm{a}}$} & \multirow{2}{*}{$\begin{array}{l}\text { Dose on back region } \\
\text { Kendall's Tau }\end{array}$} & \multirow{2}{*}{$\begin{array}{l}\text { Dose on shoulder/neck } \\
\text { Kendall's Tau }\end{array}$} & \multirow{2}{*}{$\begin{array}{l}\text { Dose on upper limbs } \\
\text { Kendall's Tau }\end{array}$} \\
\hline & & & \\
\hline Trunk moderately bent forward $\left(20-60^{\circ}\right)$ & .066 & -.066 & .070 \\
\hline Trunk strongly bent forward $\left(>60^{\circ}\right)$ & .092 & .011 & .109 \\
\hline $\begin{array}{l}\text { Static arm posture at shoulder level } \\
\text { (dominant limb) }\end{array}$ & .001 & .024 & -.054 \\
\hline $\begin{array}{l}\text { Static arm posture at shoulder level } \\
\text { (non dominant limb) }\end{array}$ & -.085 & .057 & .000 \\
\hline $\begin{array}{l}\text { Static arm posture above head level } \\
\text { (dominant limb) }\end{array}$ & -.019 & .015 & -.072 \\
\hline $\begin{array}{l}\text { Static arm posture above head level } \\
\text { (non dominant limb) }\end{array}$ & -.112 & .015 & -.039 \\
\hline $\begin{array}{l}\text { Lifting / repositioning of loads } \\
\text { between floor and waist level }(5 \mathrm{~kg})\end{array}$ & $.164^{*}$ & .136 & .130 \\
\hline $\begin{array}{l}\text { Lifting / repositioning of loads } \\
\text { between floor and waist level }(10 \mathrm{~kg})\end{array}$ & $.199 * *$ & $.207 * *$ & .126 \\
\hline $\begin{array}{l}\text { Lifting / repositioning of loads } \\
\text { between floor and waist level }(15 \mathrm{~kg})\end{array}$ & $.177^{*}$ & $.172 *$ & .132 \\
\hline $\begin{array}{l}\text { Lifting / repositioning of loads } \\
\text { between floor and waist level }(20 \mathrm{~kg})\end{array}$ & $.181 *$ & $.168^{*}$ & .147 \\
\hline $\begin{array}{l}\text { Lifting / repositioning of loads } \\
\text { between floor and waist level }(\geq 25 \mathrm{~kg})\end{array}$ & .107 & .121 & $.156^{*}$ \\
\hline $\begin{array}{l}\text { Lifting / repositioning of loads } \\
\text { between waist and head level }(5 \mathrm{~kg})\end{array}$ & $.278 * *$ & $.209 * *$ & $.169 *$ \\
\hline $\begin{array}{l}\text { Lifting / repositioning of loads } \\
\text { between waist and head level }(10 \mathrm{~kg})\end{array}$ & $.257 * *$ & $.195 * *$ & $.192 *$ \\
\hline $\begin{array}{l}\text { Lifting / repositioning of loads } \\
\text { between waist and head level }(15 \mathrm{~kg})\end{array}$ & $.186 *$ & $.192 *$ & $.154 *$ \\
\hline $\begin{array}{l}\text { Lifting / repositioning of loads } \\
\text { between waist and head level (> } 15 \mathrm{~kg})\end{array}$ & .131 & .019 & .142 \\
\hline Age $^{\mathrm{b}}$ & $.513^{* *}$ & $.389 * *$ & $.413^{* *}$ \\
\hline
\end{tabular}

${ }^{\mathrm{a}} \mathrm{n}=100 ;{ }^{\mathrm{b}} \mathrm{n}=103$

$* \mathrm{p}<.05 ; * * \mathrm{p}<.01$

\section{Results}

\subsection{Doses of mechanical exposure in relation to age}

As was to be expected, significant positive correlations between the variables "age" and "dose of me chanical exposure" have been found for all three body regions (Table 3). Dose of exposure on back region and age show the highest correlation coefficient with a moderate value of $\tau=0.513$ and high significance $(p<0.01)$. The correlations for shoul- 
der/neck and upper limbs region are also highly significant but somewhat lower in value with $\tau=0.389$ and $\tau=0.413$ respectively.

\subsection{Doses of mechanical exposure in relation to physical worker capabilities}

For a correct interpretation of the results, it has to be pointed out that higher capability ratings indicate a higher "grade of limitation" of the respective capability.

Regarding the relationship between "dose of exposure" and specific "physical capability" most of the significant correlations are present for capabilities to lift or reposition loads. Doses of mechanical exposure on all three body regions and related to the whole working life (column "Total" in Table 3 ) show significant correlations with the capabilities to lift or reposition loads between floor and waist level or between waist and head level with some exceptions.

In back region weak to low positive correlations exist $(0.164 \leq \tau \leq 0.278)$ except for a load weight of more than or equal to $25 \mathrm{~kg}$ in case of lifting between floor and waist level and a load weight of more than $15 \mathrm{~kg}$ in case of lifting between waist and head level. Capabilities to perform different body postures like trunk inclination or elevated arm postures show no significant correlations with dose of mechanical exposure on back region

For shoulder/neck region there are no significant correlations between dose of mechanical exposure and capabilities to perform awkward body postures. Capabilities in manual materials handling are showing weak to low positive correlations $(0.168 \leq \tau \leq$ $0.209)$ with dose of exposure. The exceptions are "lifting/repositioning a load of $5 \mathrm{~kg}$ as well as more than or equal to $25 \mathrm{~kg}$ between floor and waist level" and "lifting/repositioning a load of more than $15 \mathrm{~kg}$ between waist and head level".

Doses of mechanical exposure on upper limbs region (whole working life) are positively correlated with the capability to lift or reposition a load of more than or equal to $25 \mathrm{~kg}$ between floor and waist level as well as the capability to lift or reposition a load of 5,10 or $15 \mathrm{~kg}$ between waist and head level $(0.154 \leq$ $\tau \leq 0.192)$. No other significant positive correlations can be found for this body region.

When "age" is defined as control variable in calculation of partial rank correlations, there are no more significant correlations at all.

\section{Discussion and Conclusion}

\subsection{Practical implications}

The results of our study indicate that especially worker capabilities which are related to manual materials handling may be influenced by doses of mechanical exposures which should be considered when defining job rotation schemes or planning future assignments of workers to different workplaces. These capabilities are the only ones that seem to be significantly (but weakly) related to doses of mechanical exposures. In contrast, capabilities to work in awkward work postures show no significant correlation to any type of mechanical exposure examined. Hence, capabilities to perform manual materials handling seem to be more "sensitive" to mechanical exposures experienced in a work life than capabilities related to ergonomically unfavorable body postures. In production systems where tasks like lifting or repositioning of loads are prevalent, a prospective assignment of personnel (within a working shift as well as longer time intervals) that considers these types of exposure shows potential for the "conservation" of physical worker capabilities.

\subsection{Study limitations}

Due to the fact that the design of the study presented in this paper is cross-sectional and all subjects that participated were volunteers, the results presented here may be biased because of selection effects like the 'healthy worker effect' $[3-5,17,19]$. Older workers who have experienced high doses of mechanical exposure may already have left the company and only workers who are relatively "robust" against mechanical exposures remained in their jobs. However, there are findings in other studies that put the often mentioned healthy worker effect into perspective. For example Landau et al. [16] find a relatively slight decrease in different work-related functional capacities (like the maximum lifting capacity measured in $\mathrm{kg}$ ) with age in a cross-sectional study. But their study population consists of 986 patients (aged between 18 and 65 years) from a rehabilitation centre for musculoskeletal disorders that were (previously) employed in the assembly sector of industrial enterprises. Even those subjects (representing a somewhat "negative selection") with already existing orthopedic impairments show only little deficits in age. 
Another source of bias is the so called 'recall bias' discussed for example in $[6,28]$, because questionnaires about past mechanical exposures set high demands on a subjects' motivation and ability of retrospection. Several studies on self-administered questionnaires used for collection of data about past and present physical exposures at work state that the reliability and accuracy of self-reports is clearly limited $[8,25,26]$.

The dose model used in this study may be problematic to a certain degree because exposures experienced long times ago are weighted equally as exposures from the actual job. But there is a lack of published dose models for mechanical exposures at work which may have served as alternatives to the model used here.

\subsection{Suggestions for future research}

Future studies on mechanical exposure biographies should be based on a longitudinal design including a continuous or at least periodical "exposure monitoring" in order to minimize bias and augment the level of accuracy as well as reliability of data.

\section{Acknowledgements}

The authors thank the German Research Foundation (DFG) for funding this project. We would also like to thank all cooperation partners from industry and science.

\section{References}

[1] Bernard, B. P., Putz-Anderson, V., \& Burt, S. E. (1997). Musculoskeletal disorders and workplace factors: a critical review of epidemiologic evidence for work-related musculoskeletal disorders of the neck, upper extremity, and low back. U.S. Department Of Health And Human Services; Public Health Service; Centers for Disease Control and Prevention; National Institute for Occupational Safety and Health.

[2] Buckle, P., \& Devereux, J. (1999). Work-related Neck And Upper Limb Musculoskeletal Disorders. (European Agency for Safety \& Health at Work, Hrsg.). Commission of the European.

[3] Carpenter, L. M. (1987). Some observations on the healthy worker effect. British Medical Journal, 44(5), 289-291.

[4] Checkoway, H., Pearce, N., \& Kriebel, D. (2004). Research methods in occupational epidemiology. Oxford University Press, USA.

[5] Choi, B. C. . (2000). A technique to re-assess epidemiologic evidence in light of the healthy worker effect: the case of firefighting and heart disease. Journal of occupational and environmental medicine, 42(10), 1021.
[6] Coughlin, S. S. (1990). Recall bias in epidemiologic studies. Journal of Clinical Epidemiology, 43(1), 87-91.

[7] da Costa, B. R., \& Vieira, E. R. (2010). Risk factors for workrelated musculoskeletal disorders: a systematic review of recent longitudinal studies. American journal of industrial medicine, 53(3), 285-323.

[8] d' Errico, A., Gore, R., Gold, J. E., Park, J. S., \& Punnett, L. (2007). Medium-and long-term reproducibility of selfreported exposure to physical ergonomics factors at work. Applied Ergonomics, 38(2), 167-175.

[9] Elsner, G., Petereit-Haack, G., Haerting, J., Bergmann, A., Bolm-Audorff, U., Celik, S., Müller, M., Gül, A., Jendrezok, U., Ridder, S., Straub, R., Schumann, B., Liebers, F., \& Seidler A.: Fall-Kontroll-Studie zu Bandscheibenvorfällen der Halswirbelsäule durch berufliche Belastungen. Bundesanstalt für Arbeitsschutz und Arbeitsmedizin (Ed.), 2009

[10]Enríquez Díaz, J. A., Shiekirka, S., Markus, A., Frieling, E., \& Straeter, O. (2010). Chaku-Chaku assembly system - a new trend in the automotive industry: First results of the ergonomic evaluation on a case study. In W. Karwowski \& G. Salvendy (Eds.), Proceedings of the 3rd International Conference on Applied Human Factors and Ergonomics (AHFE). Miami: USA Publishing.

[11]Hagberg, M., Silverstein, B., Wells, R., Smith, M. J., Hendrick, H. W., Carayon, P., \& Pérusse, M. (1995). WorkRelated Musculoskeletal Disorders Wmsds: A Reference for Prevention. (I. Kuorinka \& L. Forcier, Eds.). Taylor \& Francis Ltd.

[12]Hartmann, B., \& Spallek, M. (2009). Arbeitsbezogene Muskel-Skelett-Erkrankungen. Arbeitsmed Sozialmed Umweltmed, 44(8), 423-436.

[13]Kendall, M. G. (1938). A New Measure of Rank Correlation. Biometrika, 30(1-2), 81 -93.

[14] Kendall, M. G. (1942). Partial rank correlation. Biometrika, 32(3-4), $277-283$.

[15] Landau, K., Rademacher, H., Meschke, H., Winter, G., Schaub, K., Grasmueck, M., Moelbert, I., Sommer, M., Schulze, J. (2008). Musculoskeletal disorders in assembly jobs in the automotive industry with special reference to age management aspects. International Journal of Industrial Ergonomics, 38(7-8), 561-576.

[16] Landau, K., Weißert-Horn, M., Presl, A., \& Brauchler, R. (publ. in progr.). Productivity and Worker Age. In S. Kumar, A. Mital, \& S. Pennathur (Hrsg.), Human Work Productivity. Boca Raton, FL: Taylor \& Francis.

[17]Li, C. Y., \& Sung, F. C. (1999). A review of the healthy worker effect in occupational epidemiology. Occupational Medicine, 49(4), 225.

[18]Lindner, M., Woldt, C., \& Kulemann, P. (2010). DGB-Index Gute Arbeit - Der Report 2010 - Wie die Beschäftigten die Arbeitsbedingunge in Deutschland beurteilen. Berlin: DGBIndex Gute Arbeit GmbH.

[19] Monson, R. R. (1986). Observations on the healthy worker effect. Journal of Occupational Medicine, 28(6), 425-433.

[20]National Research Council (NRC), \& Institute of Medicine (IOM) (Eds.). (2001). Musculoskeletal disorders and the workplace - low back and upper extremities. Washington D.C.: National Academy Press.

[21] Punnett, L., Gold, J., Katz, J. N., Gore, R., \& Wegman, D. H. (2004). Ergonomic stressors and upper extremity musculoskeletal disorders in automobile manufacturing: a one year follow up study. Occupational and environmental medicine, 61(8), 668-674.

[22] Rademacher, H., Sinn-Behrendt, A., Landau, K., Bruder, R. (2009). Development of a tool for an integrative agedifferentiated workload analysis. In: IEA 2009 (Ed.), Proceed- 
ings of the 17th World Congress on Ergonomics, Beijing, China.

[23]Rademacher, H., Bruder, R., Sinn-Behrendt, A., \& Landau, K. (2011). Identifying demographic bottlenecks for musculoskeletal risks in production areas - Implications for the design of industrial workplaces and assignment of workers. In: 10th International Symposium on Human Factors in Organisational Design and Management, April 4-6 2011, Grahamstown (South Africa).

[24] Sluiter, J. K., Rest, K. M., \& Frings-Dresen, M. H. W. (2001) Criteria document for evaluating the work-relatedness of upper-extremity musculoskeletal disorders. Scandinavian Journal of Work, Environment \& Health, 27(1), 1-102.

[25] Somville, P.-R., Nieuwenhuyse, A. V., Seidel, L., Masschelein, R., Moens, G., Mairiaux, P., \& The BelCoBack Study Group. (2005). Validation of a self-administered questionnaire for assessing exposure to back pain mechanical risk factors.
International Archives of Occupational and Environmental Health, 79(6), 499-508

[26] Torgén, M., Winkel, J., Alfredsson, L., \& Kilbom, A. (1999). Evaluation of questionnaire-based information on previous physical work loads. Scandinavian Journal of Work Environment and Health, 25, 246-254.

[27]Weichel, J. (2007, April 18). Auswirkungen berufsbiografischer Arbeitsbedingungen auf die Gesundheit und Leistungsfähigkeit im Alter. Presentation at the Symposium Vom Defizit- zum Kompetenzmodell - Stärken älterer Arbeitnehmer erkennen und fördern, 2nd Symposium of the Marie-Luise und Ernst Becker Stiftung, Bonn.

[28] Wiktorin, C., Karlqvist, L., \& Winkel, J. (1993). Validity of self-reported exposures to work postures and manual materials handling. Stockholm MUSIC I Study Group. Scandinavian Journal of Work, Environment \& Health, 19(3), 208-214. 